\title{
Ortaokul Öğrencileri İçin Konuşma Özyeterlik Ölçeği Geliştirme Çalışması
}

\author{
DOI: $10.26466 /$ opus. 935427
}

\author{
Sevil Hasırcı Aksoy* - Mehmet Ali Arıc1 ${ }^{* *}$ - Murat Kan** \\ * Dr.Öğr.Üyesi, Gaziantep Üniversitesi, Gaziantep Eğitim Fakültesi, Gaziantep/Türkiye \\ E-Posta: sevilhasirci@gmail.com ORCID: $0000-0003-1041-7558$ \\ ** Arş.Gör., Gaziantep Üniversitesi, Gaziantep Eğitim Fakültesi, Gaziantep/Türkiye \\ E- Posta: arici@gantep.edu.tr \\ ORCID: $0000-0001-9076-8205$ \\ *** Öğretmen, MEB, Gaziantep/Türkiye \\ E- Posta: kanm7227@gmail.com \\ ORCID: $\underline{0000-0003-4958-3078}$
}

Öz

Konuşma, duygu ve düşüncelerin sesler aracilğ̆yla aktarılması eylemidir. Bu eylem, toplumsal ilişkilerin sürdürülmesi ve demokratik kültürün gelişmesinde önemli bir rol oynar. Konuşma becerisinin duyuşsal göstergelerinden biri olan özyeterlik algısı bireylerin konuşma başarımları üzerinde önemli bir etkiye sahiptir. Bu araştırmanın amacı, ortaokul öğrencilerinin konuşma özyeterlik algılarını belirlenmesine yönelik geçerli ve güvenilir bir ölçme aracı geliştirmektir. Ölçme aracınn geliştirilmesinde strasılyla; madde havuzunun oluşturulması, uzman görüşlerinin eldesi, pilot uygulama, veri toplama ve veri analizi işlemleri yapılmıştır. Ölçeğin geçerlik ve güvenirliğine ilişkin çalışmalar 610 ortaokul öğrencisinden toplanan verilerle gerçekleştirilmiştir. 24 maddeden oluşan ölçek, beşli likert tipindedir. Açımlayıcı faktör analizi sonucunda maddelerin dört faktör altında toplandığı ve bu faktörlerin varyansm \%45.5'ini açıkladığı görülmüştür. Ardından doğrulayıcı faktör analiziyle modelin $R M S E A=.034, R M R=.040, S R M R=.0349$ açısından mükemmel; $A G F I=.935, C F I=.960$, GFI= .949, NFI= .909 açısından iyi uyum gösterdiği sonucuna ulaşılmıştır. Ölçeğin iç tutarllık katsayısı ise .815 olarak hesaplanmıştır. Bu bulgular ölçeğin geçerli ve güvenilir olduğunu göstermektedir.

Anahtar Kelimeler: Konuşma becerisi, konuşma özyeterlik ölçeği, ortaokul öğrencileri, geçerlik ve güvenirlik. 


\title{
Speaking Self-Efficacy Scale Development Study for Secondary School Students
}

\begin{abstract}
Speaking is the transmission of feelings and thoughts through sounds. It plays an important role in the maintenance of social relations and the development of democratic culture. Self-efficacy perception, which is one of the affective indicators of speaking skill, has an important effect on individuals' speaking performance. The aim of this study is to develop a valid and reliable scale for determining the speaking self-efficacy perceptions of secondary school students. For this purpose, respectively; establishment of an item pool, obtaining expert opinions, pilot application, data collection and data analysis procedures were carried out. The data were collected from 610 secondary school students for the validity and reliability analyses of the scale. The scale consists of 24 likert type items with five degrees. It was found that the total explained variance was $45.5 \%$ and that the items were grouped under four factors after the exploratory factor analysis. And also, the model fit indices were seen according to confirmatory factor analysis results in perfect fit (RMSEA=.034, RMR=.040, SRMR=.0349), and also in well fit in terms of $A G F I=.935, C F I=.960, G F I=.949, N F I=.909$. The internal consistency of the scale is .815. These findings show that the scale is a valid and reliable measurement tool.
\end{abstract}

Key Words: $\quad$ Speaking skill, speaking self-efficacy scale, secondary school students, validity and reliability. 


\section{Giriş}

Duygu ve düşüncelerin paylaşımını sağlayan en temel yol, anlatmaktır. Bir anlatma etkinliği olan konuşma, insanlar arasındaki iletişimi sağlayan en yaygın araç konumundadır. Konuşma, gereksinimlerin karşılanmasını olanaklı kıldığından kaçınılmaz bir eylem olarak görülür. Chaney (1998) konuşmayı "çeşitli bağlamlarda sözlü ve sözlü olmayan sembolleri kullanarak anlam oluşturma ve paylaşma süreci" (s.13) olarak tanımlar. Bir başka deyişle konuşma; bilgiyi algilama, işlemleme ve üretmeyi içeren etkileşimli bir anlam oluşturma sürecidir (Florez, 1999). Bu süreçte bilgiler amaç, konu ve sinırlara göre zihinde yapılandırılarak aktarım için seçilmekte; sıralama, sınıflama, ilişki kurma, eleştirme, çıkarımda bulunma, çözümleme-bireşim yapma ve değerlendirme işlemleriyle düzenlenerek tümcelere, sözcüklere, hecelere ve seslere dökülmektedir. Zihinde başlayan ve sözlü ifadeyle tamamlanan bu süreçte, oluşturulan düşünceler zihinde etkin bir biçimde yapılandırılır. Bu yönüyle konuşma eylemi, dili edinme sürecinde zihinsel düzenlemeyi olanaklı kılan bir öğrenme alanı olarak kabul edilmektedir (Güneş, 2007, 2014 ve 2021).

Dil yetkinliğine ilişkin önemli göstergelerden biri olan konuşma becerisi okul başarısında da belirleyici bir roldedir (Doğan, 2009; Temizyürek, 2007). Öğrencilerin iletişim kurmalarında, toplumsal çevreyle bütünleşmelerinde, duygusal açıdan kendilerini gerçekleştirmelerinde ve dolayısıyla etkileşime dayalı sınıf içi iletişim ortamının oluşturulmasında sözlü anlatım becerileri son derece önemlidir (Demir ve Gül Özdil, 2019). Konuşma, sosyalleşmeyi sağlamasıyla çocukların kendine güvenlerini artırdığ1 gibi öğretimin amaçlarının gerçekleşmesine de olanak sağlar. Çocuklar konuşma yoluyla yeni bilgileri yorumlar, sorular oluşturur, arkadaşlarının davranışlarını değerlendirir, sosyal ilişkilerini sürdürür, bilgilerini aktarır ve kişisel deneyimlerini paylaşırlar (Akyol, 2006, s.72). Bu doğrultuda, sınıf içinde ve sınıf dişında dört temel dil becerisinin geliştirilmesinin amaçlandığı Türkçe Dersi Öğretim Programı'nda, Türkiye Yeterlilikler Çerçevesinde (TYÇ) tanımlanan "anadilde iletişim" sekiz anahtar yetkinlikten biri olarak sunulmaktadır. Programda esas alınan temel yaklaşımda öğrencilerin her türlü sosyal ve kültürel bağlama uygun bir biçimde duygu, düşünce, görüş ve olguları yazılı ve sözlü olarak ifade etme ve yorumlama yetkinliğine ulaşmaları amaçlanmıştır. 
Anlatma becerilerine dönük olarak ayrıca, öğrencilerin “Türkçeyi konuşma ve yazma kurallarına uygun olarak bilinçli, doğru ve özenli kullanmalarının sağlanması" ve "duygu ve düşüncelerin sözlü ve yazılı olarak etkili ve anlaşılır biçimde ifade etmelerinin sağlanması" özel amaçlar olarak belirlenmiş ve programda bu amaçlara yönelik kazanımlara yer verilmiştir (MEB, 2019).

Konuşma becerisi genel olarak fiziksel, bilişsel ve duyuşsal olmak üzere üç boyutta ele alınmaktadır. Konuşmanın fiziksel boyutu biyolojik yap1 ve psikomotor becerilerle ilgiliyken (Yüceer, 2014) konuşmanın bilişsel boyutunu konuşma-beyin ve konuşma-bellek ilişkileri (Kemiksiz, 2016) oluşturur. Konuşmanın duyuşsal boyutunda ise konuşmaya karşı geliştirilen duyuşsal tepkiler yer alır. Bunlar; bireyin konuşmaya olan motivasyonu ve tutumu, konuşma sürecinde duyduğu kaygı ve konuşma becerisine yönelik oluşturduğu özyeterlik algısıdır (Hamzadayı, Bayat ve Gölpınar, 2018). Etkili ve yeterli bir başarım, becerileri olduğu kadar becerileri kullanmak için yeterlik inançlarını da gerektirmekte (Bandura, 1997), öğrencilerin akademik başarıları özyeterlik algı düzeylerinden etkilenmektedir (Pajares ve Miller, 1994). Bu nedenle, konuşma becerilerini geliştirme amaçlarına ulaşmak için konuşmanın duyuşsal niteliklerinin de göz önünde bulundurulması gerekir. Öğrencilerin konuşmaya dönük isteklilikleri, kendi konuşmaları hakkındaki inançları ve iletişim sürecine ilişkin endişeleri dikkatle incelenmelidir (Demirel, Türkel ve Aydın, 2020).

Özyeterlik, bireylerin başarıya ulaşmak için gerekli eylemleri planlama ve yürütme becerilerine olan inançlarını ifade eder (Bandura, 1986). $\mathrm{Bu}$ inanç güdülenme, iyi oluş ve başarının temelini oluşturur (Pajares, Johnson ve Usher, 2007, s.105). Bandura'ya (1977, 1986) göre algilanan özyeterlik; bir davranışı gerçekleştirmek için gereken kararı, gösterilen çabayı ve zorluklar karşısındaki direnmeyi belirlediğinden davranış değişikliğinin en güçlü yordayıcısıdır. Bireyler, yetkinliklerini aştığına inandıkları görev ve durumlardan kaçınırken yerine getirmeye yetkin hissettikleri işleri takip etme eğilimindedirler. Bilgi ve becerilerin uygulanmasına aracılık etmesi ve başarımın düzeyini belirlemesi bakımından özyeterlik algısı ayrıca önem taşır (Schunk, 1981, 1995).

Alanyazın incelendiğinde özyeterlik algısının geçmiş başarılar, dolay11 yaşantılar, sözel ikna ve duygusal durum olmak dört kaynaktan gelen 
bilgilerin yorumlanmasıyla biçimlendiği görülür. Geçmiş deneyimler doğrudan bilgiye dayanması nedeniyle özyeterlik üzerindeki en etkili bilgi kaynağıdır. Başarılı deneyimler özyeterlik algısını olumlu yönde etkilerken düzenli tekrar eden ya da öğrenme sürecinin erken dönemlerinde ortaya çıkan başarısızlıklar bu algıyı olumsuz etkiler. Daha zayıf bir özyeterlik kaynağı olan dolaylı yaşantılarda kişi başkalarının deneyimlerini gözlemleyerek rol modeller oluşturur. Bu gözlemler kişinin kendi yeterliklerini ölçebileceği ve başarı tahminlerini dayandırabileceği göstergeler oluşturarak davranışın zorluk derecesi hakkında bilgi verir. Bir diğer kaynak olan sözel ikna, kişileri bir davranışı gerçekleştirme yeteneğine sahip olduklarına ikna etmeye yönelik sözlü ifadeleri içerir. Kişinin kendi deneyimleri ya da örnekleriyle ilgili olmadığından önceki iki kaynaktan zayıf ve çoğunlukla diğer kaynakları desteklemek amacıyla kullanılır. Dördüncü kaynak olan duygusal durum ise en soyut olantdır. Bireyin eylemi gerçekleştirdiği sıradaki fizyolojik ve duygusal durumunun başarımı üzerindeki etkisini ifade eder. Nitekim kişiler yeterliklerini değerlendirirken fizyolojik ve duygusal durumları hakkındaki bilgileri de kullanmaktadırlar (Bandura, 1986, 1997; Pajares, 2003; Schunk ve Carbonari, 1984; van der Bijl ve Shortridge-Baggett, 2002). Ayrıca Bandura (1986), başkalarının beklentileri ve desteği gibi çevresel faktörlerin de özyeterlik üzerinde etkili olabileceğini ve bireylerin özyeterlikleri konusunda bir yargıya varırken tüm bu kaynaklardan gelen bilgileri birleştirerek bilişsel olarak işlediklerine dikkat çeker.

Özyeterlik algısı bireyleri bilişsel, duyuşsal, güdülenme ve seçim süreçleri olmak üzere dört farklı yönden etkilemektedir (Bandura, 1986, 2010). Çoğu davranış ilkin düşüncede biçimlendiğinden tahmin, planlama ve uygulama işlemleri ve bu işlemlerin denetimi bilişsel bir süreci karşılar. Olumsuzlukları yönetme konusunda yüksek yeterlik algısına sahip bireylerin daha düşük algıdaki bireylere göre daha az kaygı duymaları duyuşsal etkiyi oluşturur. Özyeterlik algısının güdülenmeye etkisi ise sonuç beklentileri üzerindeki etkisinden kaynaklanır. Güdülenme istendik sonuçların elde edilebileceğine inanılan davranışlarda ortaya çıkar (Zimmerman, 1997). Bireylerin kendi yetkinliklerine ve eylemlerinin olası sonuçlarına ilişkin inançları seçimlerinin kaynağını oluşturmaktadır. Bu seçimler aynı zamanda kişilerin yaşam akışlarını biçimlendirmekte, bu nedenle seçimleri etkileyen herhangi bir etken kişisel gelişimin 
yönünde de belirleyici olabilmektedir (van der Bijl ve ShortridgeBaggett, 2002).

Alanyazına bakıldığında temel dil becerileri ile özyeterlik algıları arasında anlamlı ilişki saptayan çalışmalar olduğu görülmektedir (Arıcı ve Dölek, 2020; Erdem, Altunkaya ve Ateş, 2017; Taş ve Balc1, 2019; Ülper ve Şirin, 2020). Bu bağlamda, konuşma becerisine dönük başarıyı artırmak, başarısızlığın nedenlerini saptamak ve gerekli çözüm önerileri geliştirebilmek için öğrencilerin konuşma becerisine ilişkin özyeterlik alg1larının belirlenmesi önem taşımaktadır.

\section{Yöntem}

$\mathrm{Bu}$ çalışmada, ortaokul öğrencilerinin hazırlıksız konuşma becerilerine yönelik, yaş düzeyine uygun bir ölçek geliştirmek amaçlanmıştır. Ölçeğin analizleri SPSS 21.0 ve AMOS 21.0 paket programları kullanılarak gerçekleştirilmiştir.

\section{Çalışma Grubu}

Bu çalışma, 2020-2021 eğitim-öğretim yılı güz döneminde Gaziantep İl Millî Eğitim Müdürlüğüne bağlı 14 farklı ortaokulda yürütülmüştür. Hazırlanan taslak formdaki madde sayısı $45^{\prime}$ tir. Bir ölçekteki madde sayısının 10 katı örnekleme ulaşılması, geçerlik-güvenirlik açısından önem taşımaktadır (Çepni, 2018; Nunnally, 1978). Bu nedenle bu araştırmada madde sayısının 10 katından fazla katılımcıya ulaşılmıştır ve araştırmanın çalışma grubunu 5-8. sınıflarda öğrenim gören toplam 610 öğrenci oluşturmuştur. Öğrencilerin cinsiyet ve sinıf düzeylerine göre dağılımı Tablo 1'de sunulmuştur.

Tablo 1. Sınıf ve Cinsiyete Göre Katılımcıların Dağılımı

\begin{tabular}{llll}
\hline & & $n$ & $\%$ \\
\hline \multirow{2}{*}{ Cinsiyet } & Kiz & 358 & 58.7 \\
& Erkek & 252 & 41.3 \\
\hline \multirow{4}{*}{ Sinif } & 5. Sinif & 125 & 20.5 \\
& 6. Sinif & 153 & 25.1 \\
& 7. Sinif & 183 & 30 \\
& 8. Sinif & 149 & 24.4 \\
\hline
\end{tabular}


Katılımcılar sınıf ve cinsiyet değişkenleri açısından incelendiğinde, kız öğrencilerin çalışma grubunun \%58.7'sini oluşturduğu görülmektedir. Sınıf düzeyi açısından ise, öğrenci sayıları birbirine yakın olmakla birlikte, en yüksek oran \%30 ile 7. sınıf öğrencilerindedir.

\section{Konuşma Özyeterlik Ölçeği'nin Geliştirilme Süreci}

Ölçme aracının geliştirilmesinde sırasıyla; madde havuzunun oluşturulması, uzman görüşüne başvurulması, pilot uygulama, veri toplama ve veri analizi işlemleri uygulanmıştır.

Ölçeğin madde havuzunun oluşturulmasında alanyazındaki çalışmalardan ve öğretmen görüşlerinden yararlanılmış, ortaokul öğrencilerinin konuşma özyeterlik algılarını belirlemeye dönük 48 maddelik bir madde havuzu oluşturulmuştur. Yazılan maddeler konuşma eğitimi ve eğitimde ölçme-değerlendirme alanlarından 8 uzman tarafından incelenmiş ve elde edilen geri bildirimler doğrultusunda 4 madde düzeltilmiş, 3 madde ise madde havuzundan çıkarılmıştır.

Maddelerin anlaşılırlık düzeylerini belirlemek amaciyla 5, 6, 7 ve 8 . sinıflardan toplam 36 öğrenciye maddeler okutulmuş ve öğrencilerden her bir maddeden ne anladıklarını açılamaları istenmiştir. Bu öğrenciler ölçeğin geçerlik ve güvenirlik çalışmalarının yapıldığı asıl uygulamaya alınmamıştır. Yapılan çalışmada öğrencilerin anlamadıkları ya da farklı anlam çıkardıkları görülen 4 madde düzeltilmiştir. Son durumda 5’li likert tipinde, 42 olumlu ve 3 olumsuz maddeden oluşan 45 maddelik bir taslak form oluşturulmuştur. Formdaki olumlu maddeler "Kesinlikle katılmıyorum" 1, "Tamamen katılıyorum" 5 biçiminde puanlanırken olumsuz ifadelere verilen yanıtlar için "Kesinlikle katılmıyorum" 5 "Tamamen katılıyorum" 1 olarak puanlanmıştır.

45 maddelik taslak form, doğrulayıcı faktör analizi için 205 ortaokul öğrencisine uygulanmıştır. Bu uygulamanın amacl, ölçülmesi istenen psikolojik niteliğin gerçeğe en yakın yapısını elde etmek amacıyla gerekli olan verileri toplamak ve çözümlemektir. Bu süreçte elde edilen Cronbach Alfa değerinin .70 ve üzerinde bir değere sahip olup olmadığına bakılır ve bu değer .70 ve üzerinde ise ölçeğin iç tutarlılığ1 olduğu söylenebilir (Seçer, 2015). Ölçeğin güvenirliğine ilişkin yapılan iç tutarlılık analizi sonucunda Cronbach Alfa değeri .929 olarak bulunmuştur. Bu 
sonuç, ölçeğin iyi düzeyde iç tutarlılığa sahip olduğu şeklinde değerlendirilebilir. Madde analizleri için elde edilen çıtılar üzerinde yapılan incelemede M6, M26, M43 ve M44 numaralı maddelerin ölçekten çıkarılması uygun görülmüştür. Sorunlu görülen maddeler çıkarıldığında ise ölçeğin iç tutarlılığına ilişkin Cronbach Alfa değeri .945'e yükselmiştir. Böylece ölçek, 41 madde ile açımlayıc faktör analizi için 610 ortaokul öğrencisine uygulanmıştır.

\section{Bulgular}

Bu bölümde ortaokul öğrencilerine yönelik konuşma özyeterlik ölçeğinin geçerlik ve güvenirlik çalışmalarından elde edilen bulgulara yer verilmiştir.

\section{Ortaokul Öğrencilerine Yönelik Konuşma Özyeterliği Ölçeğinin Açımlayıcı Faktör Analizi Sonuçları}

Örneklem büyüklüğünün faktör analizine uygunluğuna karar vermek için Kaiser-Meyer-Olkin (KMO) testinin sonucuna bakılmıştır. KMO testi, 0-1 aralığında sayısal bir değer vermekte ve örneklem büyüklüğünün faktör analizine uygunluğunu açıklamaktadır (Şencan, 2005). KMO testi sonucunda bulunan .939 değerine göre veri seti faktör analizine "mükemmel uyum" (Şencan, 2005) göstermektedir. Faktör analizlerinin yapılabilmesi için veri setindeki maddeler arasındaki korelasyonların yeterli düzeyde olması gerekmektedir. Bunun için Barlett küresellik testi yapılmaktadır. Barlett testi ile ki-kare değeri elde edilir ancak testin sonucunun yorumlanması için anlamlılık değerine bakılır. Anlamlılık değeri .05 'ten küçük ise veri setindeki değişkenlerin (maddelerin) tutarlı olduğu (Pett, Lackey ve Sullivan, 2003, s.77), bu değerlerin anlamlılık değerinin kabul edilebilir olduğu (Field, 2009) ve veri setinden faktör çıkarılabileceği yorumu yapılır (Şencan, 2005). Yapılan test sonucunda [ $\chi 2=4960.366$; $\mathrm{df}=351, \mathrm{p}=.00$ ] verilerin açımlayıcı faktör analizi (AFA) için uygun olduğu sonucuna ulaşılmıştır.

Faktör yüklerinin alt eşiği .40 olarak hesaplanmış, "ölçüt olarak faktör yüklerinin toplam varyansı açılama yüzdesinin \%40'ın üzerinde olma- 
sı" (Kline, 1994) göz önünde bulundurulmuştur. Alanyazına bakıldığında (Büyüköztürk, 2002; Şencan, 2005; Çokluk, Şekercioğlu ve Büyüköztürk, 2010), faktör örüntüsünün oluşturulmasında değiş̧en faktör yüklerinin alt kesme noktası olarak .30 ile .40 arasında alınabileceği belirtilmektedir. Ayrıca Tavşancıl'a (2002) göre faktör analizi sonucunda elde edilen varyans oranları ne kadar yüksekse ölçeğin faktör yapısı o kadar güçlü olmaktadır.

Faktör analizinde özdeğeri 1 ya da 1'den daha büyük olan faktörler, önemli faktörler olarak kabul edilmektedir (Büyüköztürk, 2002, s.479). Bu araştırmada özdeğeri 1.00'den büyük dört faktör olduğu belirlenmiştir. Bu amaçla ölçeğe uygulanan temel bileşenler analizi sonuçlarına ilişkin olarak elde edilen faktörler ve bu faktörlerde yer alan 27 maddeye ilişkin ait faktör yükleri Tablo 2' deki gibidir.

Tablo 2. Konuşma Becerisi Özyeterlik Ölçeği Maddelerinin Faktör Yükleri Matrisi

\begin{tabular}{llll}
\hline Madde No & Faktör1 & Faktör2 & Faktör3 \\
\hline Madde1 & & .491 & Faktör4 \\
Madde2 & & & .512 \\
Madde3 & & & .555 \\
Madde4 & & & .579 \\
Madde5 & & & .692 \\
Madde7 & & & .441 \\
Madde10 & & .579 \\
Madde25 & & .578 & .406 \\
\hline Madde12 & & .432 & \\
Madde14 & & .608 & \\
Madde15 & & .530 & \\
Madde16 & & .632 & \\
Madde17 & & .638 & \\
Madde20 & & .428 & \\
Madde22 & & & \\
Madde29 & & & \\
\hline Madde8 & & \\
Madde23 & .692 & & \\
Madde24 & .651 & & \\
Madde26 & .419 & & \\
Madde30 & .530 & & \\
Madde33 & .551 & & \\
Madde34 & .582 & & \\
Madde35 & .679 & & \\
\hline Madde39 & & & \\
Madde40 & & & \\
Madde41 & & & \\
\hline
\end{tabular}


Tablo 2'ye bakıldığında, faktör yük değerlerinin birinci faktörde (duyuşsal) yer alan maddeler için .405 ile .692 arasında, ikinci faktörde (içerik) yer alan maddeler için .428 ile .638 arasında, üçüncü faktörde (dilötesi) yer alan maddeler için .406 ile .692 arasında ve dördüncü faktörde (etkilenme) yer alan maddeler için .611 ile .657 arasında değiştiği görülmektedir. Temel bileşenler analizi ve Varimax döndürme tekniği sonucunda toplam varyansın \% 45.554'ünü açılayan ve z değeri 1'in üstünde olan 4 faktörün değerlerine Tablo 3 'te yer verilmiştir.

Tablo 3. Konuşma Becerisi Özyeterlik Ölçeği Açımlayıcı Faktör Analizi Sonuçları

\begin{tabular}{lccc}
\hline Faktörler & Özdeğer & Varyans Yüzdesi & $\begin{array}{c}\text { Toplam Varyans } \\
\text { Yüzdesi }\end{array}$ \\
\hline Duyuşsal & 8.357 & 30.952 & 30.952 \\
İçerik & 1.514 & 5.608 & 36.560 \\
Dil-ötesi & 1.252 & 4.636 & 41.196 \\
Etkilenme & 1.177 & 4.358 & 45.554 \\
\hline
\end{tabular}

Tablo 3 incelendiğinde, birinci faktörün toplam varyansın \%30.952'sini açıkladığı ve özdeğeri en yüksek faktör (8.357) olduğu görülmektedir. Diğer faktörler birbirine benzer oranda özdeğere sahip ve en üstten en alta sıralandığında içerik, ikinci sırada yer alan faktördür. Varyans yüzdesi ise $\% 5.608$ 'dir. Bunu dil-ötesi ve etkilenme izlemektedir. Belirlenen dört faktöre ilişkin korelasyon değerleri Tablo $4^{\prime}$ te sunulmuştur.

Tablo 4. Faktörler Arasındaki Korelasyon Değerleri

\begin{tabular}{lcccc}
\hline & Duyuşsal & İçerik & Dil-ötesi & Etkilenme \\
\hline Duyuşsal & 1 & .696 & .626 & .466 \\
İçerik & .696 & 1 & .661 & .434 \\
Dil-ötesi & .626 & .661 & 1 & .377 \\
Etkilenme & .466 & .434 & .377 & 1 \\
\hline
\end{tabular}

Tablo 4'e göre ölçme aracının faktörleri arasındaki ilişki anlamlı ve orta düzeydedir. Korelasyon katsayısının 69 ile .30 aralığında olması "orta düzeyde" bir ilişki olduğunu göstermektedir (Büyüköztürk, 2014). 


\section{Ortaokul Öğrencilerine Yönelik Konuşma Özyeterliği Ölçeğinin Doğ- rulayıcı Faktör Analizi Sonuçları}

Ortaokul öğrencilerine yönelik geliştirilen konuşma özyeterlik ölçeğinin AFA sonuçlarına göre belirlenen 4 faktörlü 27 maddelik yapısını doğrulamak için yapılan analiz sonucunda 3 madde (M3, M20, M25) ölçekten çıkarılmıştır. Modele ait doğrulayıcı faktör analizi (DFA) sonuçları Şekil 1'de gösterilmiştir:

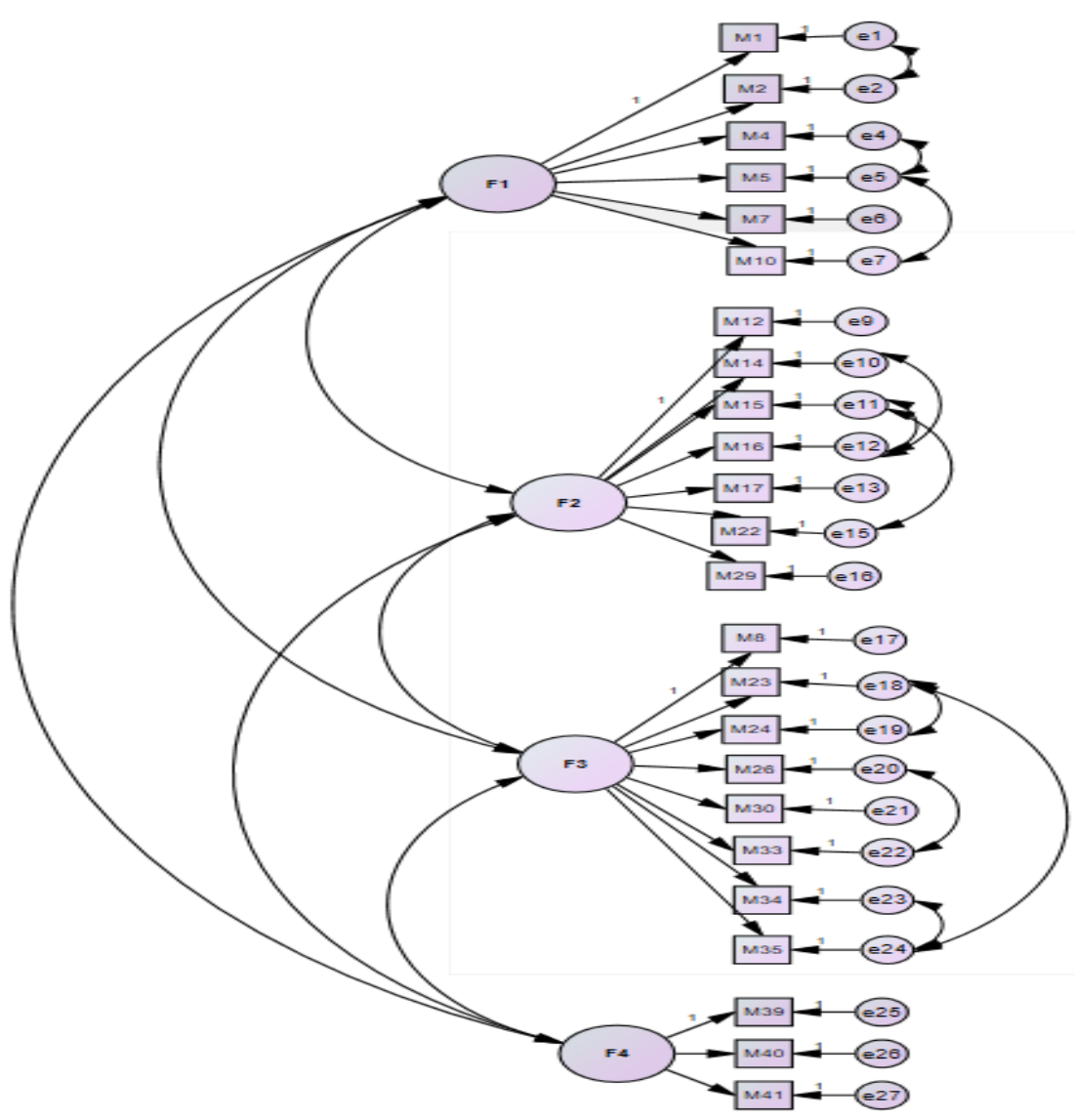

Şekil 1. Ölçeğe ilişkin path diyagramı 
DFA kapsamında ilk olarak özgün ölçeğin geçerlik çalışmalarında kullanılan uyum indekslerine bakılmış ve bu bilgilere Tablo 5'te yer verilmiştir.

Tablo 5. Ölçeğe İlişkin DFA Sonuçları

\begin{tabular}{|c|c|c|c|c|c|c|c|c|c|}
\hline$\chi^{2}$ & sd & RMSEA & RMR & SRMR & GFI & AGFI & NFI & CFI & IFI \\
\hline 401.374 & 236 & .034 & .04 & .0349 & .949 & .935 & .909 & .96 & .96 \\
\hline $\begin{array}{l}\text { Kabul } \\
\text { edilebilir } \\
\text { uyum } \\
\text { değerleri }\end{array}$ & $\begin{array}{c}\chi 2 / \mathrm{sd}<3 \\
\text { mükem- } \\
\text { mel }\end{array}$ & $\begin{array}{c}0 \leq \\
\text { RMSEA } \\
\leq .08\end{array}$ & $\begin{array}{c}0 \leq \\
\text { RMR } \\
<.05 \\
\text { ideal }\end{array}$ & $\begin{array}{c}0 \leq \\
\text { SRMR } \\
\leq .05\end{array}$ & $\begin{array}{c}.90 \leq \\
\text { GFI } \leq \\
1.00\end{array}$ & $\begin{array}{c}.85 \leq \\
\text { AGFI } \\
\leq 1.00\end{array}$ & $\begin{array}{c}.90 \leq \\
\mathrm{NFI} \leq \\
1.00\end{array}$ & $\begin{array}{l}.95 \leq \\
\text { CFI } \leq \\
1.00\end{array}$ & $\begin{array}{l}.95 \leq \\
\mathrm{IFI} \leq \\
1.00\end{array}$ \\
\hline
\end{tabular}

(Schermelleh-Engel, Moosbrugger ve Müller, 2003; Sümer, 2000; Tabachnick ve Fidell, 2001)

Yapılan doğrulayıcı faktör analizinde öncelikle p değerine bakılmış ve bu değerin .00 düzeyinde anlamlı olduğu görülmüştür. Bununla birlikte modelin $\chi 2 / \mathrm{sd}=1.701$, RMSEA $=.034, \mathrm{RMR}=.040, \mathrm{SRMR}=.0349$ aç1sindan mükemmel; AGFI= .935, CFI= .960, GFI= .949, NFI= .909 açısından iyi derecede uyum gösterdiği belirlenmiştir.

\section{Ortaokul Öğrencilerine Yönelik Konuşma Özyeterliği Ölçeğinin Gü- venirlik Analizi Sonuçları}

Ölçeğin güvenirlik değerlerini belirlemek amacıyla Cronbach Alfa iç tutarlılık katsayısı $(\alpha)$ hesaplanmıştır. Ölçeğin bütünü için bu değer .815 olarak bulunmuştur. Faktörlere ilişkin $\alpha$ değeri Tablo 6' daki gibidir.

Tablo 6. Faktörlerin Güvenirlik Katsayıları

\begin{tabular}{lcc}
\hline Faktör & Madde Sayıs & $\alpha$ \\
\hline 1 (Duyuşsal) & 8 & .757 \\
2 (İçerik) & 7 & .724 \\
3 (Dil-ötesi) & 6 & .738 \\
4 (Etkilenme) & 3 & .846 \\
\hline
\end{tabular}

Tablo 6'ya bakıldığında güvenirlik katsayılarının 1, 2, 3 ve 4. faktörler için sırasıyla $.757, .724, .738$ ve .846 olduğu görülmektedir. Bu değerler ölçeğin maddelerinin kendi içinde tutarlı ve ifade ettiği özyeterlik algısını yansitma derecesinin "kabul edilebilir ve iyi düzeyde" (Ergin, 1995) olduğunu göstermektedir.

Ölçek maddelerinin ayırt ediciliğini belirlemek amacıyla alt ve üst grupların ortalama puanları arasındaki farka bakılmış ve bunun için 
bağımsız gruplar $\mathrm{t}$ testi yapılmıştır. Elde edilen sonuçlara Tablo 7'de yer verilmiştir.

Tablo 7. Faktörlerin ve Ölçeğin Alt-Üst Grup Bağımsız Örneklem T-Testi Sonuçları

\begin{tabular}{|c|c|c|c|c|c|c|c|}
\hline Faktörler & Gruplar & $\mathbf{N}$ & Ortalama & $\begin{array}{c}\text { Standart } \\
\text { Sapma }\end{array}$ & $\begin{array}{l}\text { Standart } \\
\text { Hata Ort. }\end{array}$ & $t$ & $\mathrm{p}$ \\
\hline \multirow{2}{*}{ Duyuşsal } & Üst Grup & \multirow{2}{*}{610} & 4.6564 & .23888 & .01860 & \multirow{2}{*}{78.911} & \multirow{2}{*}{.000} \\
\hline & Alt Grup & & 2.9876 & .45303 & .03527 & & \\
\hline \multirow{2}{*}{ İçerik } & Üst Grup & \multirow{2}{*}{610} & 4.6736 & .22211 & .01729 & \multirow{2}{*}{63.310} & \multirow{2}{*}{.000} \\
\hline & Alt Grup & & 2.9576 & .52104 & .04056 & & \\
\hline \multirow{2}{*}{ Dil-ötesi } & Üst Grup & \multirow{2}{*}{610} & 4.7622 & .25244 & .01965 & \multirow{2}{*}{68.154} & \multirow{2}{*}{.000} \\
\hline & Alt Grup & & 2.8734 & .55529 & .04323 & & \\
\hline \multirow{2}{*}{ Etkilenme } & Üst Grup & \multirow{2}{*}{610} & 4.4990 & .27716 & .02158 & \multirow{2}{*}{68.154} & \multirow{2}{*}{.000} \\
\hline & Alt Grup & & 2.7190 & .38594 & .03005 & & \\
\hline
\end{tabular}

Tablo 7 incelendiğinde, özyeterlik ortalama puanları açısından alt grupla üst grup arasında anlamlı bir farklılık olduğu görülmektedir $(p<.05)$. Ölçek maddelerinin $t$ değeri bakımından üst grup lehine anlamlı bir fark olduğu belirlenmiştir. Elde edilen bu bulgular, ortaokul öğrencilerinin konuşma özyeterlik algılarını belirlemeyi amaçlayan bu ölçeğin alt grup ve üst grubu ayırt edebildiğini, başka bir deyişle ölçeğin ayırt ediciliğe sahip olduğunu göstermektedir.

\section{Tartışma, Sonuç ve Öneriler}

Bu çalışmada ortaokul öğrencilerinin konuşma becerilerine yönelik geçerli ve güvenilir bir özyeterlik ölçeği geliştirilmiştir. Ölçek geliştirme sürecinde öncelikle alanyazın taraması yapılmış, hazırlanan maddeler doğrultusunda taslak ölçek oluşturulmuştur. Uzman görüşü ve pilot deneme aşamasının ardından gerekli düzeltmeleri yapılan 5'li likert tipindeki ölçek, 610 ortaokul öğrencisine uygulanmıştır. Ölçeğin analizleri SPSS 21.0 ve AMOS 21.0 paket programları kullanılarak gerçekleştirilmiştir. Çalışmada KMO değeri .939 olarak belirlenmiştir. Bu değerin .90 üzerinde olması "mükemmel" olarak yorumlanmaktadır. Barlett testi değeri $\left[{ }^{*} \chi_{2}=4960.366 ; \mathrm{df}=351, \mathrm{p}=.00\right]$ ise anlamlı bulunmuştur. Bu sonuçlar veri setinin açımlayıcı faktör analizi için uygun olduğunu göstermektedir. Açımlayıcı faktör analizi sonrası çıkarılan 3 madde ile 24 maddelik bir ölçek elde edilmiştir. Ölçekte "duyuşsal", "içerik", "dil-ötesi" ve "etkilenme" olmak üzere toplam dört faktör yer almaktadır. Ölçekte 8'i birinci, 7'si ikinci, 6'sı üçüncü ve 3'ü dördüncü faktörde yer alan 24 
maddenin faktör yükleri .405 ile .692 arasındadır. Ölçeğin Cronbach Alfa iç tutarlılık katsayısı .815 olarak hesaplanmıştır. Alt-üst grup bağımsız örneklem t testi sonuçları açısından üst grup lehine anlamlı bir fark bulunmuştur. Bu durum ölçeğin alt ve üst gruplarının ayırt edicilik özelliğine sahip olduğunu göstermektedir.

Alanyazın incelendiğinde dört temel dil becerisine yönelik çeşitli sayıda özyeterlik algı ölçeği geliştirme çalışması (Aydın, 2013; Aydın, Demircan ve İnnalı, 2015; Büyükikiz, 2012; Demir, 2014; İşci ve Akkaya, 2018; Katrancı ve Melanlığlu, 2013; Öztahtalı ve Şahin, 2020; Sallabaş, 2013; Şahin ve Öztahtalı, 2019; Şengül, 2013; Ülper, Yaylı ve Karakaya, 2013; Yılmaz Soylu ve Akkoyunlu, 2019) yapıldı̆̆ı görülmektedir. Dinleme becerisine yönelik geliştirilen ölçeklerden Aydın, Demircan ve İnnalı'nın (2015) çalışması ortaokul düzeyine, İşci ve Akkaya'nın (2018) çalışması ise iki dilli öğrencilere yöneliktir. Okuma becerisine yönelik geliştirilen ölçeklerden Şahin ve Öztahtalı'nın (2019) hedef kitlesi ortaöğretim öğrencileriyken Ülper, Yaylı ve Karakaya'nın (2013) hedef kitlesini 8-9-10-11 ve 12. sınıf öğrenci oluşturmaktadır. Yazma becerisine yönelik geliştirilen ölçeklerden Büyükikiz'in (2012) hedef kitlesi iki dilli öğrenciler, Demir'in (2014) hedef kitlesi 8. sınıf öğrencileri, Şengül (2013) ile Yılmaz Soylu ve Akkoyunlu'nun (2019) hedef kitlesi ise ortaokul öğrencileridir. Konuşma becerisine yönelik geliştirilen özyeterlik ölçeklerine bakıldı̆̆ında Aydın (2013) ile Katrancı ve Melanlığlu'nun (2013) hedef kitlesinin öğretmen adayları, Sallabaş’ın (2013) hedef kitlesinin Türkçeyi yabancı dil olarak öğrenen ileri düzey öğrencileri, Öztahtalı ve Şahin'in (2020) hedef kitlesinin ise ortaöğretim öğrencileri olduğu görülür. Geliştirilen özyeterlik ölçekleri incelendiğinde, okuma ve yazma beceri alanlarında ortaokul düzeyine yönelik ölçeklerin olmasına karşın konuşma beceri alanında bu düzeye yönelik bir ölçme aracının bulunmayışı dikkat çekmektedir. Bu çalışmayla birlikte alanyazındaki bu boşluğun giderilmesi amaçlanmıştır.

\section{Etik Kurul Onay Bilgileri (The Ethical Committee Approval)}

Bu çalışma, Gaziantep Üniversitesi Sosyal ve Beşeri Bilimler Etik Kurulu'nun 19.03.2021 tarih ve E-73628654-604.01.01-27575 sayılı kararı ile araştırma ve yayın etiğine uygun olarak gerçekleştirilmiştir. 


\title{
EXTENDED ABSTRACT
}

\section{Speaking Self-Efficacy Scale Development Study for Secondary School Students}

\author{
Sevil Hasırcı Aksoy- Mehmet Ali Arıc1- Murat Kan \\ Gaziantep University-Gaziantep University-MONE
}

Speaking skill plays a significant role for individuals to prove themselves in society and develop their personality. This skill has cognitive, affective and physical dimensions. Self-efficacy, as a part of the affective dimension, is an important indicator through which individuals can measure their speaking competency and build their success predictions. There are studies in literature reporting a significant relationship between basic language skills and self-efficacy perceptions. With the development of scales for four basic skills, the target groups of the ones developed for speaking skill are different: teacher candidates, advanced students who learn Turkish as a foreign language, and secondary school students. Among available self-efficacy perception scales, there are scales for reading and writing skills at secondary school level, but it is noteworthy that a measurement tool for speaking skill at this level has not been developed. This study aims to fill this gap in the literature. Within this respect, it is important to identify self-efficacy perceptions of students in terms of speaking skill in order to enhance their performance in speaking, to reveal the causes of failure and to propose necessary solutions. The aim of this study is to develop a valid and reliable scale of impromptu speaking skills suitable for the age level of secondary school students.

\section{Method}

In this study was aimed to develop a valid and reliable scale for the speaking skills of middle school students. For this purpose, respectively; establishment of an item pool, obtaining expert opinions, pilot application, pre-application, data collection and data analysis procedures were carried out. 
It is important to reach a sample size 10 times greater than the number of items in a scale for validity and reliability. Therefore, in this study, the number of participants was ten times greater than the number of items, and the study group consisted of 610 students studying in grades $5-8$. In terms of class and gender, girls constituted $58.7 \%$ of the study group, and the 7th graders had the highest rate with $30 \%$ followed by similar rates. In the development of the measurement tool, a total of six steps were followed including developing an item pool, seeking expert opinion, piloting, pre-testing, data collection and data analysis respectively. For the development of the item pool of the scale, studies in the literature and teachers' opinions were reviewed, and an item pool of 48 items was created to identify self-efficacy perceptions of secondary school students. The items were then examined by 8 experts from the fields of assessment and evaluation in education and teaching speaking, and 4 items were revised in line with the feedback obtained, and 3 items were removed from the pool. In order to examine clarity levels of the items in the scale, 36 students from the 5th- 8th grades were asked to read the items and were asked to express what they understood from each item. These students were excluded from the final implementation of the scale in which validity and reliability tests of the scale were carried out. Following this, 4 items which the students did not seem to understand or interpreted differently were corrected. Subsequently, a 5-point Likert-type scale trial form was created with 45 -items including 42 positive and 3 negative items. "Strongly disagree" and "totally agree" options were scored as 1 and 5 respectively for positive items while "absolutely disagree" and "completely agree" options were scored as 5 and 1 respectively for negative statements. For the piloting of the scale, the 45 -item trial scale form was applied to 205 secondary school students in Gaziantep. The aim of the piloting is to collect and analyze the data necessary to obtain the most realistic structure of the psychological quality to be measured. As a result of the findings derived from the item analysis, items numbered M6, M26, M43 and M44 were excluded from the scale. Cronbach alpha value for the internal consistency of the scale increased to .945 when the problematic items were removed. So, the scale was considered to be ready for validity and reliability test with 41 items. 


\section{Result and Discussion}

In order to determine whether the sample size was suitable for factor analysis, the result of the Kaiser-Meyer-Olkin (KMO) test was used. The value of .939 calculated through KMO test indicated that the data set had a perfect fit with the factor analysis. Correlations between items in the data set must be sufficient to perform factor analysis. In order to check this, Bartlett test of sphericity was conducted. As a result of the test, the data was found to be suitable for exploratory factor analysis [ $\chi 2=4960.366 ; \mathrm{df}=351, \mathrm{p}=.00]$. As a result of the principal components analysis and varimax rotation technique, 4 factors and 27 items were obtained, which explained $45,554 \%$ of the total variance, with a $z$-score above 1 . The relationship between factors was significant and moderate. A total of 3 items (M3, M20, M25) were removed from the scale as a result of the analysis performed to verify the 27-item structure with 4 factors, according to EFA results of the self-efficacy scale developed for secondary school students, and the following results were achieved. Firstly, the $\mathrm{p}$ value of .00 was found to be significant. Moreover, the model was found to be perfect in terms of $\chi 2 / \mathrm{df}=1.701$, RMSEA $=0.034$, $R M R=0.040, S R M R=0.0349$, and have a perfect fit in terms of AGFI $=0.935$, $\mathrm{CFI}=0.960, \mathrm{GFI}=0.949, \mathrm{NFI}=0.909$.

Cronbach alpha internal consistency coefficient $(\alpha)$ was calculated to measure the reliability values of the scale. This value was .815 for the whole scale. The reliability coefficients of the scale were .757, .724, .738 and .846 for factors 1, 2, 3 and 4, respectively. These values indicated that the items of the scale had an internal consistency and reflected the selfefficacy perception at an acceptable and a good level. Following that, in order to test the distinctiveness of the scale items, the difference between the average scores of the lower and upper groups was examined through independent groups t-test. There was a significant difference between the self-efficacy average scores of the lower and upper group $(p=.00<.05)$. A significant difference was found in favor of the upper group in terms of the $t$-value of the scale items. These findings showed that the selfefficacy scale for speaking skills can distinguish between upper and lower groups, which means that it has internal validity. As a result of the 
findings, a valid and reliable scale for speaking self-efficacy levels was developed for grades 5-8.

\section{Kaynakça/References}

Akyol, H. (2006). Türkçe öğretim yöntemleri. Ankara: Kök Yayıncllk.

Arıcı, M. A. ve Dölek, O. (2020). Ortaokul öğrencilerinin yazma özyeterlik alg1 düzeyleri ile yazma başarımları arasındaki ilişki. Ana Dili Eğitimi Dergisi, 8(4), 1204-1217.

Aydın, İ. S. (2013). Öğretmen adaylarının konuşma öz yeterliklerine ilişkin ölçek geliştirme çalışması. Akdeniz Eğitim Araştırmalan Dergisi, 14, 33-46.

Aydın, İ. S., Demircan, U. ve İnnall, Ö. (2015). Ortaokul öğrencilerinin dinleme/izleme öz yeterlik algılarına yönelik ölçek geliştirme çalışmaS1. International Journal of Languages' Education and Teaching, 1420-1435.

Bandura, A. (1977). Self-efficacy: toward a unifying theory of behavioral change. Psychological Review, 84, 191-215.

Bandura, A. (1986). Social foundations of thought and action. A Social Cognitive Theory. Prentice Hall: Englewoods Cliffs, NJ, 23-28.

Bandura, A. (1997). Self-efficacy: The exercise of control. New York: Freeman.

Bandura, A. (2010). Self-efficacy. The Corsini encyclopedia of psychology, 1-3.

Büyükikiz, K. (2012). Türkçeyi ikinci dil olarak öğrenen yabancilar için yazma becerisi öz yeterlilik ölçeğinin geliştirilmesi: Geçerlilik ve güvenilirlik çalışması. Mustafa Kemal Üniversitesi Sosyal Bilimler Enstitüsü Dergisi, 9(18), 69-80.

Büyüköztürk, Ş. (2002). Faktör analizi: Temel kavramlar ve ölçek geliştirmede kullanım. Kuram ve Uygulamada Ĕ̆itim Yönetimi, 32, 470-483.

Büyüköztürk, Ş. (2014). Sosyal bilimler için veri analizi el kitabı (19. baskl). Ankara: PegemA Yayınları.

Chaney, A. L. (1998). Teaching Oral Communication in Grades K-8. Boston: Allyn \& Bacon.

Çepni, S. (2018). Araştırma ve proje çalı̧̧malarına giriş (8. baskı). Ankara: Pegem Akademi Yayınları.

Çokluk, Ö., Şekercioğlu, G. ve Büyüköztürk, Ş. (2010). Sosyal bilimler için çok değişkenli istatistik. Ankara: Pegem Akademi.

Demir, T. (2014). Yazma öz yeterlik ölçeğinin Türkçe formunun geçerlik ve güvenirlik çalışması. E-Kafkas Ĕ̆itim Araştırmaları Dergisi, 1(2), 28-35. 
Demir, S. ve Gül Özdil, B. (2019). Öğretmen görüşlerine göre ortaokul öğrencilerinin konuşma becerileri. Abant İzzet Baysal Üniversitesi Eğitim Fakültesi Dergisi, 19(3), 865-881.

Demirel, M. V., Türkel, A. and Aydın, İ. S. (2020). Speaking self-efficacy beliefs of Turkish University students. Cypriot Journal of Educational Sciences, 15(3), 399-411.

Doğan, Y. (2009). Konuşma becerisinin geliştirilmesine yönelik etkinlik önerileri. Türk Ĕ̈itim Bilimleri Dergisi, 7(1), 185-204.

Erdem, İ., Altunkaya, H. ve Ateş, A. (2017). Türkçeyi yabancı dil olarak öğrenenlerin okur özyeterlikleri ile okuduğunu anlama becerileri arasındaki ilişki. International Journal of Language Academy, 5(4), 74-86.

Ergin, Y. D. (1995). Ölçeklerde geçerlik ve güvenirlik. M.Ü. Atatürk Ĕ̆itim Fakültesi Eğitim Bilimleri Dergisi, 7, 125-148.

Field, A. (2009). Discovering statistics using SPSS (and sex and drugs and rock ' $n$ ' roll) (Third Edition). London: Sage Publication.

Florez, M. C. (1999). Improving adult English language learners' speaking skills. National center for ESL literacy education. Washington DC: Applied linguistics center.

Güneş, F. (2007). Türkçe öğretimi ve zihinsel yapılandırma. Ankara: Nobel Yayınlari.

Güneş, F. (2014). Konuşma öğretimi yaklaşım ve modelleri. Bartın Üniversitesi Eğitim Fakültesi Dergisi, 3(1), 1-27.

Güneş, F. (2021). Türkçe öğretimi yaklaşımlar ve modeller. Ankara: Pegem Akademi.

Hamzadayı, E., Bayat, N. ve Gölpınar, Ş. (2018). Konuşma kaygı düzeyi ile konuşma başarımı arasındaki ilişki. Journal of Language Education and Research, 4(2), 75-85.

İşci, C. ve Akkaya, N. (2018). İkidilli öğrencilerin Türkçe dersi dinleme becerisine ilişkin özyeterlikleri: Ölçek geliştirme çalışması. Electronic Turkish Studies, 13(27), 891-905.

Katrancı, M. ve Melanlığlu, D. (2013). Öğretmen adaylarına yönelik konuşma öz yeterlik ölçeği: Geçerlik ve güvenilirlik çalışması. The Journal of Academic Social Science Studies, 6(6), 651-665.

Kemiksiz, Ö. (2016). Doğrudan öğretim modeliyle beşinci sinıföğrencilerinin konuşma becerilerinin geliştirilmesi. (Doktora tezi). Çanakkale Onsekiz Mart Üniversitesi, Çanakkale.

Kline, P. (1994). Easy guide to factor analysis. London: Routledge. 
Millî Eğitim Bakanlığı [MEB] (2019). Türkçe öğretim programı. Ankara: Millî Eğitim Bakanlığı.

Nunnually, J.C. (1978). Psychometric theory. NewYork: McGraw-Hill Companies.

Öztahtalı, İ. ve Şahin, E. (2020). Etkili konuşma özyeterlik algı ölçeğinin geliştirilmesi: Geçerlilik ve güvenirlik çalışması. Electronic Turkish Studies, 15(1), 565-582. DOI: 10.29228/TurkishStudies.39967

Pajares, F. and Miller, M. D. (1994). Role of self-efficacy and self-concept beliefs in mathematical problem solving: A path analysis. Journal of Educational Psychology, 86, 193-203.

Pajares, F. (2003). Self-efficacy beliefs, motivation, and achievement in writing: A review of the literature. Reading $\mathcal{E}$ Writing Quarterly, 19(2), 139-158.

Pajares, F., Johnson, M. J. and Usher, E. L. (2007). Sources of writing self-efficacy beliefs of elementary, middle, and high school students. Research in the Teaching of English, 42(1), 104-120.

Pett, M. A., Lackey, N. R. and Sullivan, J. J. (2003). Making sense of factor analysis: the use of factor analysis for instrument development in health care research. London and Thousand Oaks: Sage Publications.

Sallabaş, M. E. (2013). Türkçeyi yabancı dil olarak öğrenenler için konuşma öz yeterlik ölçeği: Geçerlilik ve güvenirlilik çalışması. Dumlupınar Üniversitesi Sosyal Bilimler Dergisi, 36, 261-270.

Schermelleh-Engel, K., Moosbrugger, H. and Müller, H. (2003). Evaluating the fit of structural equation models: Tests of significance and descriptive goodness-of-fit measures. Methods of Psychological Research Online, 8(2), 23-74.

Schunk, D. H. (1981). Modeling and attributional effects on children's achievement: A self-efficacy analysis. Journal of Educational Psychology, 73, 93105.

Schunk, D. H. and Carbonari, J. (1984). Self-efficacy models. In J. Matarazzo, S. Weiss, J. Herd, N. Miller, \& S. Weiss (Eds.). Behavioral health: A handbook of health enhancement and disease prevention. New York, NY: John Wiley \& Sons.

Schunk, D. H. (1995). Self-efficacy and education and instruction. In Self-efficacy, adaptation, and adjustment (p.281-303). Springer, Boston, MA.

Seçer, İ. (2015). Psikolojik test geliştirme ve uyarlama süreci: SPSS ve Lisrel uygulamaları. Ankara: Anı Yayıncilık.

Sümer, N. (2000). Yapısal eşitlik modelleri: Temel kavramlar ve örnek uygulamalar. Türk Psikoloji Yazıları, 3(6), 49-74. 
Şahin, E. ve Öztahtalı, İ. (2019). Etkili okuma özyeterlik algı ölçeğinin geliştirilmesi: Geçerlilik ve güvenirlik çalışması. Electronic Turkish Studies, 14(4), 2685-2703. DOI: 10.29228/TurkishStudies.23378.

Şencan, H. (2005). Sosyal ve davranışsal ölçümlerde güvenilirlik ve geçerlilik. Ankara: Seçkin Yayıncllı.

Şengül, M. (2013). Ortaokul öğrencilerine yönelik yazma öz yeterlikleri ölçeği geliştirme çalışması. Türkiye Sosyal Araştırmalar Dergisi, 171(171), 81-94.

Tabachnick, B. G. and Fidell, L.S. (2001). Using multivariate statistics (4. baskl). Boston: Ally \& Bacon.

Taş, H. ve Balcı, A. (2019). 8. sınıf öğrencilerinin yazma öz yeterlilik algıları ile öykü yazma becerileri üzerine bir araştırma. Okuma Yazma Ĕ̆itimi Araştırmaları, 7(1), 51-70.

Tavşancıl, E. (2002). Tutumların ölçülmesi ve SPSS ile veri analizi. Ankara: Nobel Yayıncilik.

Temizzyürek, F. (2007). Progressing speaking ability in second level of elementary education. Ankara University Journal of Faculty of Educational Sciences (JFES), 40(2), 113-131. DOI: 10.1501/Egifak_0000000175.

Ülper, H., Yayll, D. ve Karakaya, İ. (2013). Okur özyeterlik ölçeğinin geliştirilmesi. Ahi Evran Üniversitesi Kırşehir Eğitim Fakültesi Dergisi (KEFAD), 14(1), 85-100.

Ülper, H. ve Şirin, A. N. (2020). Okuma anlama düzeyleriyle özyeterlik algısı arasındaki ilişki bağlamında ortaokul öğrencilerinin görünümleri. $P a-$ mukkale Üniversitesi Ĕ̆itim Fakültesi Dergisi, 48, 1-14. DOI: 10.9779/pauefd.487556.

van der Bijl, J. J. and Shortridge-Baggett, L. M. (2002). The theory and measurement of the self-efficacy construct. Research and Theory for Nursing Practice 15(3), 189-207.

Yılmaz Soylu, M. ve Akkoyunlu, B. (2019). Yazma öz-yeterlik ölçeğinin Türkçeye uyarlanması. Kastamonu Eğitim Dergisi, 27(5), 2233-2242.

Yüceer, D. (2014). Türkçe ö̆gretmenliği birinci sınıf öğrencilerinin hazırlıksız konuşma becerileri üzerine bir araştırma (Yüksek lisans tezi). Gazi Üniversitesi, Ankara.

Zimmerman, B. J. (2000). Self-efficacy: An essential motive to learn. Contemporary educational psychology, 25(1), 82-91. 
Ek 1- Konuşma Özyeterlik Ölçeğinin Son Hali

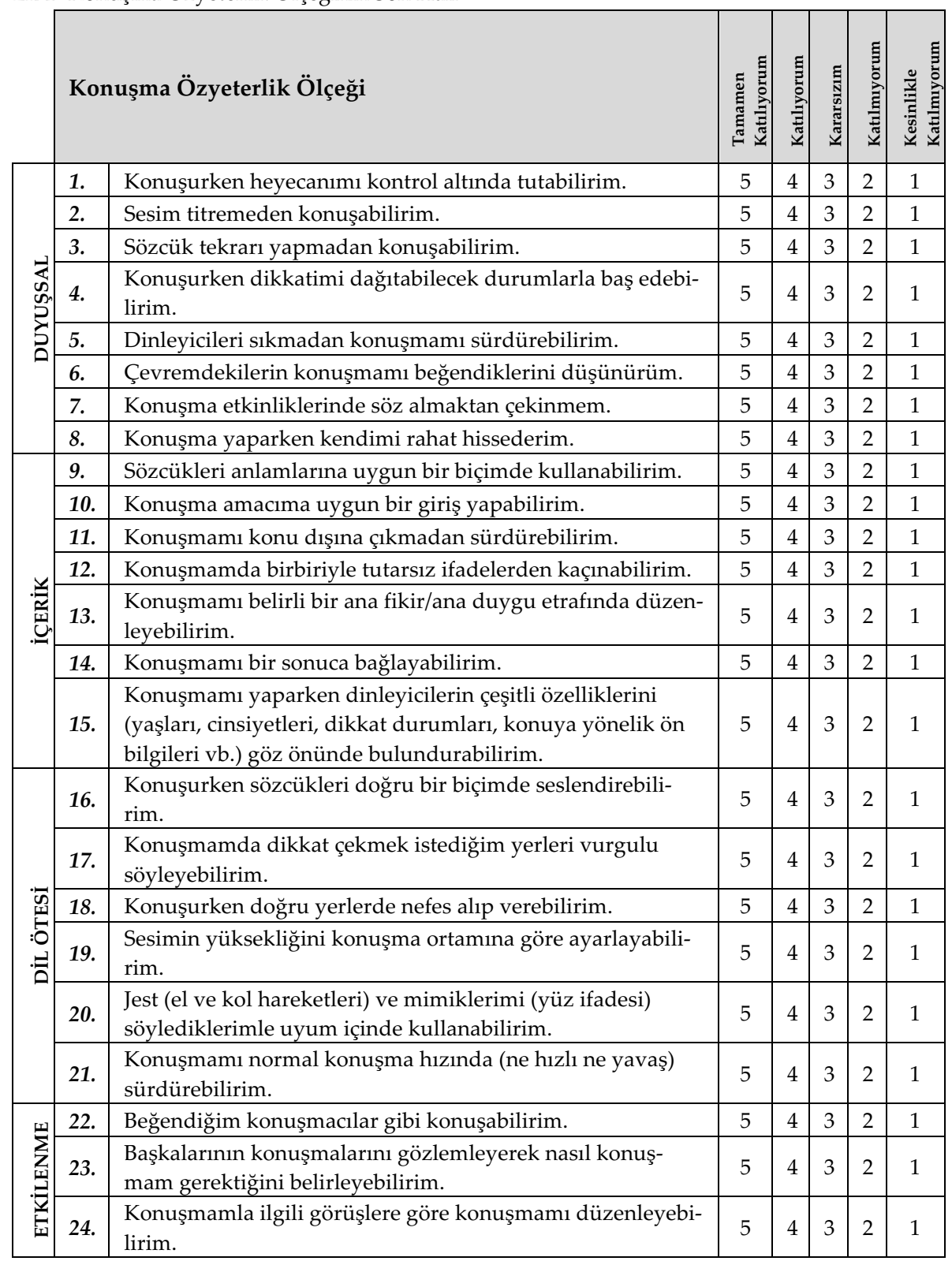




\section{Kaynakça Bilgisi/Citation Information}

Hasırcı Aksoy, S., Arıcı, M. A. ve Kan, M. (2021). Ortaokul öğrencileri için konuşma özyeterlik ölçeği geliştirme çalışması. OPUSUluslararası Toplum Araştırmaları Dergisi, 18(41), 3631-3653. DOI:10.26466/opus.935427. 